An Investigation of Potable Water Supply Problems in Akinima Community 


\title{
An Investigation of Potable Water Supply Problems in Akinima Community, Ahoada West Local Government Area of Rivers State, Nigeria
}

\author{
V.C. Nnodu, S. U. Onwuka, E.U. Anyaeze and N. A. Emem \\ Department of Environmental Management \\ Nnamdi Azikiwe University, Awka \\ P.M.B 5025, Anambra State \\ E-Mail:-Nnoduvc@Yahoo.Com
}

\begin{abstract}
The Millennium Development Goals (MDGs) recognizes clean water as a major factor that determines development and promotes livelihood and human well-being, thus it set time-bound target for overcoming non -availability and non-potability of drinking water. A Scenario that is prevalent in developing countries including Nigeria. The aim of this paper is to investigate the potability of drinking water in Akinima Community, a rural community in Ahoada West Local Government Area (LGA) of Rivers State. The community like many other rural communities in Nigeria has no pipe-borne water supply. The major sources of drinking water are harvested rainwater, water from boreholes, and rivers. These sources are indentified to have varied problems of contamination and pollution, which range from high levels of chemical and microbiological contamination of harvested rainwater and rivers respectively, to saline intrusion into river water sources. Point sources and non-point sources of water contamination/pollution are common. With the current state of affairs meeting the MDGs target of "Halving, by 2015, the proportion of people without sustainable access to safe drinking water" is a mirage. The research design for the study is basically survey design and experimental design. The instruments used for investigation are questionnaire survey, face to face interview and observation. Experimentation was done in the laboratory to investigate physical, chemical and microbiological samples of drinking water from the households in Akinima community. Both primary and secondary data are applied for the study. The sample size is statistically determined using Taro Yamani's formula for a finite population. The basic sampling unit (BSU) is the household. Sampling techniques applied are both systematic sampling and random sampling for selection of house-types and households respectively. Descriptive and inferential statistics are applied to investigate the data. Major findings revealed that the three major drinking water sources are not safe for drinking, because the values are significantly difference from the National Drinking Water Quantity Standard (NDWQS) 2007. The paper recommends the development of technologies that should harness rainwater harvesting and the introduction of active Civil Society Organization (CSOs) interventions/participation in rural water supply in Akinima Community among others.
\end{abstract}


Keywords: Potable Water, Potability, Harvested rainwater, rivers, boreholes, civil society organization (CSOs), National Drinking Water Quality Standard (NDWQS)

\section{BACKGROUND TO THE PAPER}

Water, a substance comprising two molecules of hydrogen and one molecule of oxygen $\left(\mathrm{H}_{2} \mathrm{O}\right)$ is the most essential element next to air for human survival. The human body is a water machine running primarily on water and minerals. By weight, human body is about $72 \%$ water. Naturally, the quality of water man consumes affect the overall state of health. Every healing and life giving process happens in our body through water. The human blood, the very substance of human existence is more than $83 \%$ water, flowing through our body distributing nutrients, oxygen and antibodies on demand.

The efforts to improve potable water quality continued into the $21^{\text {st }}$ Century when the United Nations Assembly set time-bound targets for overcoming non-availability and non-potability of drinking water, in what is described as Millennium Development Goals (MDGs). Among other Benchmarks, the MDGs' Goal No. 7, target 10 is: 'halve, by 2015, the proportion of people without sustainable access to safe drinking water and basic sanitation'. The year of reference for this goal is 1990. In order to meet the water supply and sanitation target, an additional 260,000 people per day up to 2015 should gain access to improved water sources (WHO/UNICEF, 2004). The situation is more precarious in rural areas.

Expanding access to water and sanitation is a moral and ethical imperative rooted in the cultural and religious traditions of communities around the world. The MDGs also recognizes clean water as a major factor that determines development. Water and basic sanitation powerfully demonstrates the linkages between the multifaceted targets set under the MDGs, ranging from the eradication of extreme poverty and hunger; achievement of universal primary education; promotion of gender equality and empowerment of woman; reduction of child mortality; improvement of maternal health; combating HIV/AIDS, malaria and other diseases; ensuring environmental sustainability; to developing a global partnership for development (www.un.org/documents/ga/res/55/a.55r002.pdf-A/RES/55/2).

In the light of the foregoing, it is important that several studies be embarked upon to assess rural water potability with a view to improving the quality and quantity of rural water supply in particular; and bridging the wide gap of non-accessibility towards meeting the MDG targets for Nigeria by 2015. In order to achieve this, the paper is presented in seven sections. Section one discusses the background to the paper. Sections two and three discuss the statement of problem and study area respectively. Section four is the conceptual bases of the paper, while section five is the methodology. 
Section six discusses the research findings and section seven is the conclusion and recommendations.

\section{Statement of the Problem}

The lack of safe water for use is one of the major problems causing threat to the lives of many rural dwellers. The situation in Akinima Community in Ahoada West Local Government Area (LGA) of River State is not different. There is no pipe-borne water supply. The sources of drinking water are varied and these sources are associated with contamination and pollution at various levels. In association with other sources, River Orashi stands out as the main source of drinking water supply to the dweller of the rural community of Akinima. The problems of poor water quality and scarcity are very acute during the dry season, since the rivers are rain-fed. Harvested rainwater is a predominant source of drinking water during the rainy season. Borehole water supply, also contribute to the drinking water requirements.

There are two outstanding problems affecting these sources of potable water in the area. These are microbiological contamination and chemical pollution. Orashi River and its tributaries are contaminated with waste products from different sources, including point and non-point contamination. Defecation of human excreta directly into the river, washing and bathing, and also the use of poisonous chemicals for fish-catch are some point sources of contamination. Non-point contamination sources are oilspills from various crude oil wells and in-falling of atmospheric fallout in combination with rainfall directly into the river during the rainy season.

Roof-intercepted rainwater that is harvested in massive tanks and other receptacles are contaminated by rust and/or dirt from roof-tops and from storage facilities. Also physical and chemical particulate matter in the atmosphere is other non-point sources of contamination. Borehole water is contaminated by two major non-point sources that were identified; these are through salt water intrusion and aquifer pollution by chemicals that percolate to the ground water.

The crux of the matter is that all the sources of water supply to Akinima community are problematic, and there is no pipe-borne water supply. The implication of this state of affairs is the high incidence of water related diseases; and what is more worrisome is the inability of the rural dwellers to help themselves, because of their associated low earning capacity. Water treatment methods are crude, the inhabitants use handkerchiefs to filter the water, and then drop potash alum $\left(\mathrm{KAl}\left(\mathrm{SO}_{4}\right)_{2}\right)$ to cause coagulation or flocculation. The impurities clump together to form big particles of dirt or flocs which settle down rapidly. Then the water is strained locally to remove the flocs. While such crude treatment methods may remove physical pollutants, chemical and microbiological pollutants are still untreated.

It is against these problems, and also in the current world focus of meeting the MDG Goal 7-halving by 2015, the number of people without safe drinking or potable water, -that this study was embarked upon in 
Akinima Community. Hence, this study examined the quality of river, rain and borehole water sources and compared all three sources, with a view to identifying which of the sources should be better harnessed. The study also investigated the prevalence of water-borne diseases in the community and attempted to establish a relationship between the prevalence of water-borne diseases and the quality of water ingested. The study also proffered some remedial measures for improvement.

\section{Aim and Objectives of the Paper}

The aim of this study is to examine the level of potability of drinking water sources in the rural setting of Akinima in Ahoada Local Government Area.

To achieve this aim, the study objectives are:

- $\quad$ To identify the various sources of potable water (drinking water).

- To determine the potability of the major sources of drinking water

\section{Research Hypothesis}

Based on the study problems and the objectives, the following null hypothesis were formulated and tested:

- That there is no significant difference between the physical, chemical and microbiological parameters for rivers, boreholes and mean harvested rainwater quality and the National Drinking Water Quality Standard (NDWQS, 2005).

- That there is no significant difference among the quality of drinking water from river, mean boreholes and mean harvested rainwater quality.

\section{Conceptual Bases of the paper}

The concept on which this study is hinged is water quality. This concept is categorized into potable water and non-potable water. Potable water is that which is fit for human consumption, and can also be called drinking water (Nijavallirlt and Sathaye, 2002). According to Tebutt (1990), potable water is one that is safe to drink, pleasant to taste and usable for domestic purposes. It must not be corrosive to metal pipes and should not form scales on cold or hot water systems. This ascertain was supported by Rosegrant et al (2002) who affirmed that the above assurance could only be given when good quality control is established. Hence potable water must meet the WHO standard for drinking water, evolved over the years, as knowledge of nature and effects of various contaminants grow (WHO, 1996).

Throughout history, the quality of drinking water has been a factor in determining human welfare (Bhatia, 2002). The negative aspect of water signifies adversity and its total absence, inadequacy or unwholesomeness has a direct effect on public health and environmental aesthetics (Ekop, 1994). Cunningham and Cunningham (2002) stated that clean drinking water and 
basic sanitation are necessary to prevent communicable diseases and to maintain a healthy quality of life.

Water that is not fit for drinking is non-potable. Non-potability of drinking water is described as unwholesome. The unwholesome nature of water is a direct aftermath of pollution. Poppe and Rence (1997) defined water pollution as the impairment or contamination of water bodies such as lakes, rivers, oceans and groundwater caused by human activities which are harmful to man, plant and animal organisms. Thompson and Turk (2005) defined water pollution as the reduction in the quality of water by the introduction of impurities. A polluted river may run full to the banks, yet it may be toxic to aquatic wildlife and unfit for human use. Non-potable water may be fit for other uses such as agricultural, industrial or institutional wateruses, and even other domestic water uses except for drinking. Thus nonpotability of water does not categorize it as waste-water.

A hydraulic connection exists between streams, rivers, groundwater and springs. This hydraulic connection is expressed as the hydrologic cycle. The hydrologic cycle is defined as the constant circulation of water among the sea, the atmosphere and the land. It is possible for pollutants/contaminants to be circulated from the surface water and land to the groundwater through infiltration and subsequent percolation of polluted water from point-sources and non-point sources of pollution. The atmosphere is polluted by particulates emitted into the atmosphere and these contaminants are circulated around the environment. The major sources of water pollution are many, these include municipal, industrial, agricultural and natural phenomena such as in-washing of silts, sand and gravel from soil erosion.

Sources of water pollution are classified into point-sources and non-point sources. Point-sources are referred to as pollution which arises from a specific site such as a septic tank, a pipe emitting sludge from a factory into water bodies or a specific toxic dump-site discharging toxic substances into the environment. Non-point sources are referred to as those that do not originate from a single discrete source; rather they originate from scattered, dispersed and diffused sources of pollutants. For example oil spills, pollutants/contaminants associated with rainfall, rainfall associated with flared gases to form toxic substances that fall on water surfaces or land, or even on vegetation. Depending on the potential of the pollutants, they biomagnify and /or bioaccumulation in organisms as they constantly ingest them.

\section{Study Area}

Akinima community in Ahoada West Local Government Area (LGA) in Rivers State is the study area. It lies between longitude $6^{\circ} 28^{\prime} \mathrm{E}$ and $6^{\circ} 30^{\prime} \mathrm{E}$ and latitude $5^{\circ} 5^{\prime} \mathrm{N}$ and $5^{\circ} 10^{\prime} \mathrm{N}$ of the equator. It is bounded in the North by Joinkarama community, in the south by Oruama community, in the west by Okordia zarama community and to the east by river Orashi (Fig 1). Akinima 
community is made up of four major settlement areas; these are Omu-Oguma, Omu-Ukurosomo, Omu-Agenimo and Omu-Osu.

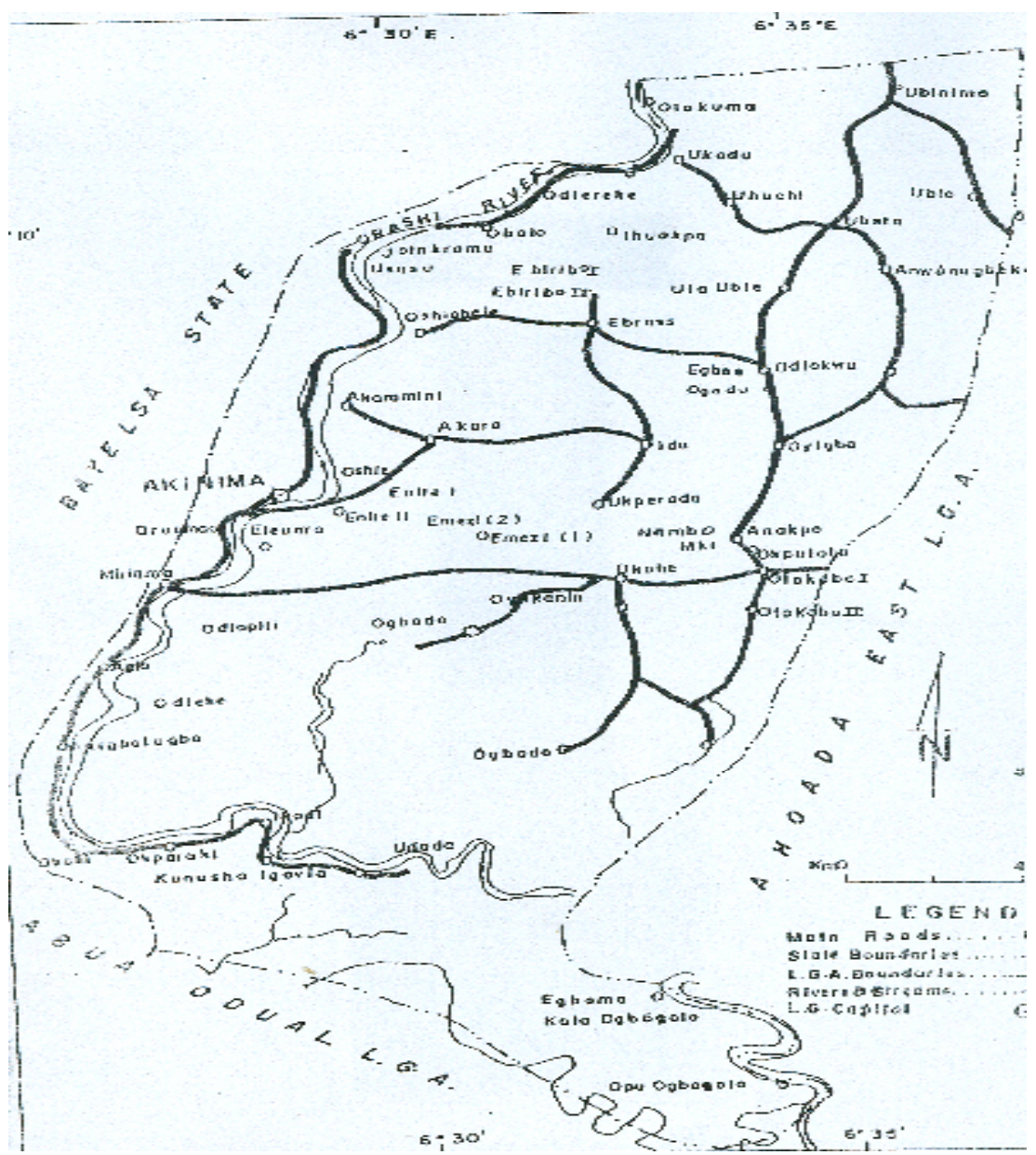

Fig 1: Map of Ahoada West Local Government Area Showing Akinima Community.

The study area is discussed under two broad characteristics, namely physical and human characteristics. Under the physical characteristics this paper discusses the climate, topography, geology, drainage and vegetation. The climatic type experienced in the area is equatorial climate; this is because of its position in respect to latitudinal location within the globe. Although it is 
said that equatorial south is a region of no season, because there is no marked dry or rainy season. But this is not strictly the case; there are two seasons, namely the dry and wet (rainy) season. The dry season starts from november to february, while the rainy season lasts from march to october with its peak at June/July. The dry season are normally warmer compared to other periods of the year. The distinction between these two seasons is governed by the amount and frequency of the rainfall. The average daily maximum temperature is about $30^{\circ} \mathrm{C}$, while the average minimum temperature is about $24^{\circ} \mathrm{C}$. Night temperature rarely falls below $21^{\circ} \mathrm{C}$. Rainfall amounts vary from $1500 \mathrm{~mm}$ to $3750 \mathrm{~mm}$. Since the study area is located in the south of Nigeria, precisely in the Niger Delta region, it experiences rainfall throughout the year, because of the prevailing south west maritime winds blowing across the Atlantic Ocean towards the coast of Guinea. There is no month without rainfall of at least $25 \mathrm{~mm}$. The rainfall is convectional in character. The area has a relative humidity of over $80 \%$ because of its nearness to the Atlantic Ocean and the prevailing moisture laden south-west winds blowing towards the guinea coast. The maximum relative humidity is $96 \%$, while the minimum relative humidity is $71 \%$.

The topography of Akinima can be described as a low-lying, rolling area. The geology is predominantly of sedimentary origin, comprised mainly of the sandstone Formation. This makes a suitable aquifer for large water retention capacity. The major surface water for potable purposes is the Orashi River. It is a tributary of river Niger. The sandstone units of the study area are the origin of surface water bodies that flows towards the south in one direction. There is normally increase in volume of water in the river during the rainy season. Naturally, the river overflows its banks from august to october annually, with its peak in september. By october it attains a state of dynamic equilibrium, then begins to retreat by november. It reduces its volume during the dry season regaining its constant nature about $1 \mathrm{~km}$ wide. The river flows towards extreme south to adjourn into Sombreiro River in Abonnema.

Human characteristics are discussed under the following: population, language and socioeconomic factors. The population of the community according to census figure of 2006 is 20,194; while the figure for Ahoada west LGA is 249,425 (NPC, 2006). The people of this community speak Engenni as their tribal language typically noted as Ogua language. The main socioeconomic activities of the inhabitants are farming, sand mining, local crafting, rubber extracting from rubber trees and other construction works. Crude oil exploration and extraction is another major operation in the area. Crops grown by farmers include cassava, sweet potatoes, yam, okra and other vegetables. Palm trees are common in this area, thus the production of palm oil and palm wine tapping are common activities.

Hunting of wild animals is also a common activity. The nature of the vegetation resulted in the abundance of a diversity of bush animals. Fishing is another major occupation practiced by the inhabitants of Akinima community. However, this activity has been greatly affected by frequent oil spillages. There are few animal rearers and poultry farms that are locally made. 


\section{Drinking Water Sources in Akinima Community}

The common sources of drinking water to the dwellers of Akinima community are harvested rainwater, groundwater from boreholes and river water from river Orashi. The inhabitants mostly prefer rainwater for drinking because they believe that the rainwater is free from impurities. Gutters are created on rooftops through which rainwater is channeled into storage facilities such as tanks, drums and buckets. Since there is no month without rainfall, it is more or less a dependable source of drinking water to the community. Following the increased dependence of harvested rainwater in the rainy season, borehole water and river water particularly from river Orashi, have the highest prevalence usage in the months of January and February, when water supply from rainfall is at its lowest.

\section{METHODOLOGY}

The research design is basically survey design. The instruments used for investigation are questionnaire survey, face-to-face interviews and observation. The target population is the population of Akinima community which is 20,194 (NPC, 2006). The sample size is statistically determined using Taro Yamani's formula for a finite population. The basic sampling unit (BSU) is the household. Assuming a conventional house size of six persons, the total number of households is obtained by dividing the total population by six, giving a total of 3366. with a target household size of about 3366 , the sample size for investigation based on a level of significance (or limit of tolerable error) of 0.05 is 358 . this implies that a total of 358 questionnaires were distributed for the study. The strategy adopted in order to arrive at a good representation of the household is through systematic sampling technique. The streets on which the households dwelt were selected randomly; however each household unit studied was selected through systematic sampling. One household was randomly selected on every third house on each street sampled.

Table 1 shows the total number of questionnaire distributed and the percentage rate of return.

Table 1: Questionnaire Distributed and Percentage Return Rate.

\begin{tabular}{|l|l|l|l|l|l|}
\hline S/n & Areas & $\begin{array}{l}\text { Number of } \\
\text { questionnaires } \\
\text { Distributed }\end{array}$ & $\begin{array}{l}\% \text { number of } \\
\text { questionnaires } \\
\text { Distributed }\end{array}$ & $\begin{array}{l}\text { Number of } \\
\text { questionnaires } \\
\text { returned }\end{array}$ & $\begin{array}{l}\% \text { number of } \\
\text { questionnaires } \\
\text { returned }\end{array}$ \\
\hline 1 & Omu- & 90 & 25.14 & 85 & 23.74 \\
2 & Oguma & 90 & 25.14 & 88 & 24.58 \\
3 & Omu- & 89 & 24.86 & 89 & 24.86 \\
4 & Ukurosoimo & 89 & 24.86 & 85 & 23.74 \\
& Omu-Osu & & & & \\
& Omu - & & & & \\
& Agenima & & 100.00 & 347 & 96.92 \\
\hline & Total & 358 & & & \\
\hline
\end{tabular}

Source: Author's Fieldwork (2008). 
The percentage rate of return is 96.92 . To ensure maximum return rate, the questionnaire were collected promptly, except for a few that were misplaced by some respondents that were absent from their homes at the time of this research.

The research method also involved laboratory analysis of water samples from the three predominant sources of drinking water. Water samples were collected from the households surveyed. Harvested rainwater, river water and borehole water samples were collected from the households. Physical, chemical and microbiological parameters of the water samples were analyzed. The physical parameters investigated include temperature, turbidity, colour, taste and odour. Others include total dissolved solid (TDS), total suspended solid (TSS) and total solid (TS), and electrical conductivity. The chemical parameters analyzed were $\mathrm{pH}$ (Hydrogen ion concentration), total hardness, copper $\left(\mathrm{Cu}^{2+}\right)$, sulphate $\left(\mathrm{SO}_{4}{ }^{2-}\right)$, iron $\left(\mathrm{Fe}^{2+}\right)$, ammonia $\left(\mathrm{NH}_{3}{ }^{+}\right)$, Barnum $(\mathrm{Ba})$, manganese $\left(\mathrm{Mn}^{2+}\right)$, magnesium $\left(\mathrm{mg}^{2+}\right)$, Zinc $\left(\mathrm{Zn}^{2+}\right)$, nitrate $\left(\mathrm{NO}_{3}^{-}\right)$, nitrite $\left(\mathrm{NO}_{2}\right)$, lead $\left(\mathrm{Pb}^{2+}\right)$, chloride $\left(\mathrm{Cl}^{-}\right)$. Fluoride $\left(\mathrm{F}^{-}\right)$, arsenic $(\mathrm{As})$, cadmium $(\mathrm{cd})$, mercury $(\mathrm{Hg})$, and total organic carbon content (TOC). The biological parameters include the total coliform count (TCC) and the feacal coliform count (FCC). Information on health records were collected from both the respondents and the clinics and hospitals they visited.

These data sources constitute the primary data. Secondary data were obtained from both published and unpublished materials such as books, periodicals, journals and magazines. Information was also sourced from health centres, national population commission and the 2007 National Drinking Water Quality Standard document.

Oral interviews and observational studies were employed to buttress the questionnaire survey. Oral interviews were employed to gather information concerning the water sources to know the point where water for drinking is collected from the river and the boreholes, and the method employed by the respondents for rainwater harvesting. Observational study was employed to examine the activities carried out in the river that might lead to pollution of the various drinking water sources.

\section{Method of Laboratory Analysis}

For the physical parameters, the temperatures of the samples were measured with mercury thermometer dipped into the water for five minutes before reading the values calibrated in celcius $\left({ }^{\circ} \mathrm{C}\right)$. Odour parameter was tested by smelling. The colours were determined by mere observation using platinum cobalt standard (Pt-co). The samples were tasted to determine the taste. Turbidity was determined using a turbidimeter. Total dissolved solids were determined using pocket TDS meter.

The chemical characteristics were determined using the HACH, DR 2500 spectrophotometer, Hach Company (2002-2004). The spectrophotometer is an automated system that has manual, which specifies procedures and reagents for each chemical parameter being measured. 
Barium was determined using Bariver (R) 4. Barium reagent powder pillow. Arsenic analysis was determined using silver diethyldithiocarbonate method. Mercury was tested using $\mathrm{HgEx}$ reagent 3 foil pillow and $\mathrm{HgEx}$ reagent 4 foil pillow and $\mathrm{Hg}$ Ex 6 foil pillow reagent. Cadmium level was determined using cadian method. Copper was determined by bicinchonicate method, using cuver 1 copper reagent powder pillow. Nitrate $\left(\mathrm{NO}_{3}\right)$ was determined using Nitraver 5 nitrate reagent, sulphate $\left(\mathrm{SO}_{4}{ }^{2-}\right)$ was determined using sulfaver IV reagent powder pillow. Hardness which constitutes calcium and magnesium was determined by calmagite colorimetric method used for detecting $\left(\mathrm{CaCO}_{3}\right)$. Lead was determined using PAR method. Iron $\left(\mathrm{Fe}^{2+}\right)$ was determined using ferrover iron reagent and $\mathrm{pH}$ was determined using a $\mathrm{pH}$ meter. Microbiological parameters determined included the total Coliform count and the feacal coliform count. The method used was membrane filtrate and culturing method.

Both descriptive and inferential statistical methods were applied to analyze the data. The mean which is a measure of central tendency was applied to determine averages; proportions were determined by applying percentages. Inferential statistics applied included the chi-square test $\left(\chi^{2}\right.$-test), the ANOVA test (Analysis of variance). Hypothesis I was tested by applying the $\chi^{2}$-test, hypothesis II was tested by applying the ANOVA test.

\section{Results and Discussion of Findings}

This section deals with the presentation of data obtained from questionnaire survey, field observation and laboratory analyses. Also discussion of research objectives and hypotheses tested are presented.

Objective 1: To identify the various sources of drinking water.

The findings to this objective are represented in table 2. The table presents the responses collated; from the questionnaire survey.

Table 2 shows that $32 \%$ of the respondents depend on harvested rainwater, $23 \%$ depend on borehole, while $36 \%$ depend on river water. $5 \%$ and $4 \%$ rely on pond and sachet water respectively. The findings show that there is a high dependency on river / stream water in Akinima community. This is in agreement with the findings of Nnodu et al. (2008), in a study carried out in another rural setting of Aguluezechukwu in Aguata LGA of Anambra State. Here also Aguluezechukwu community is a rural area with no pipe-borne water supply, wherein alternative sources included river water, harvested rainwater, and tanker-truck water supply from boreholes in surrounding semi-urban areas. River water showed the highest percentage of patronage, followed by harvested rainwater and then boreholes. Akinima community exhibited a similar performance trend. The use of sachet water $(4 \%)$ and pond $(5 \%)$ are uncommon. 
V.C. Nnodu, S. U. Onwuka, E.U. Anyaeze and N. A. Emem

Table 2: Percentage Responses on the Sources of Drinking Water in Akinima Community.

\begin{tabular}{|c|c|c|c|c|c|c|c|c|c|c|}
\hline \multirow[t]{3}{*}{ Sources } & & & \multicolumn{4}{|c|}{ Frequency $(\mathrm{F})$} & & & \multirow{2}{*}{\multicolumn{2}{|c|}{$\begin{array}{l}\text { Total } \\
\text { Observation }\end{array}$}} \\
\hline & \multicolumn{2}{|c|}{ OGU } & \multicolumn{2}{|c|}{ OKU } & \multicolumn{2}{|c|}{ OSU } & \multicolumn{2}{|c|}{$\mathrm{OAG}$} & & \\
\hline & $\mathrm{F}$ & $\%$ & $\bar{F}$ & $\%$ & $\bar{F}$ & $\%$ & $\mathrm{~F}$ & $\%$ & $\mathrm{~F}$ & $\%$ \\
\hline Harvested Rainwater & 38 & 45 & 22 & 25 & 26 & 29 & 25 & 30 & 111 & 32 \\
\hline Borehole & 13 & 15 & 19 & 22 & 25 & 28 & 23 & 27 & 80 & 23 \\
\hline River/stream & 27 & 31 & 39 & 44 & 28 & 31 & 31 & 36 & 125 & 36 \\
\hline Pond & 3 & 4 & 6 & 7 & 7 & 8 & - & - & 16 & 5 \\
\hline Sachet water & 4 & 5 & 2 & 2 & 3 & 4 & 6 & 7 & 15 & 4 \\
\hline Total & 85 & 100 & 88 & 100 & 89 & 100 & 85 & 100 & 347 & 100 \\
\hline
\end{tabular}

Source: Authors' Field work (2008)

Legend: OGU:- Omu:- Oguma; OKU:- Omu-Ukurosomio; OSU:- Omo-Osu; OAG-Omu-Agenimo .

Objective 2: To determine the potability of the various sources of drinking water.

The findings to this objective are represented in table 3 . This has to do with the quality of the drinking water sources. Table 3 shows the water quality of the three major sources of drinking water in the community, namely rivers $(36 \%)$, harvested rain water $(32 \%)$ and borehole (23\%). Table 3, displays the physical, chemical and microbiological parameters of water samples that were analyzed.

From table 3 , it is observed that the true colour unit (TCU) ranges from 6.40 TCU for borehole water to $27.00 \mathrm{TCU}$ for river water. The TCU for harvested rainwater is 11.00 . The harvested rainwater and borehole water are below the NDWQS (2007), while the TCU for the river water is higher than the acceptable standard, ironically it is the drinking water source most often patronized. Taste and odour for borehole water and river water sources are objectionable, while that for harvested rainwater are unobjectionable.

The temperature ranges of the water sources are $20^{\circ} \mathrm{C}$ for harvested rainwater, $24^{\circ} \mathrm{C}$ for borehole water and $28^{\circ} \mathrm{C}$ for the river water samples, which are all suggested to be amblent. Turbidity ranges from 24 NTU for harvested rainwater to $36 \mathrm{NTU}$ for river water, while turbidity for borehole water is 10 NTU. These indicate that all sources, have values higher than the NDWQS (2007) which is 5 NTU. Turbidity values are a reflection of the TSS and TS. The TS for river water is $637.20 \mathrm{mg} / \mathrm{l}$, which is in agreement with the high turbidity values. TS values for harvested rainwater are $843.95 \mathrm{mg} / \mathrm{l}$ and for borehole water it is $1013.10 \mathrm{mg} / \mathrm{l}$. These values are also in agreement with the high turbidity values.

Conductivity value is an indicator of the presence of dissolved salts. Conductivity values range from $1150.4 \mu S / 1$ for harvested rainwater, to 1138. $\mu \mathrm{S} / 1$ for borehole and $1401.5 \mu \mathrm{S} / 1$ for rainwater. These values are higher than the NDWQS (2007) which is $1000 \mu \mathrm{s} / \mathrm{l}$. The $\mathrm{pH}$ values fall within the acceptable standard for borehole water sources $(\mathrm{pH}=6.65)$. However, for harvested rainwater $(\mathrm{pH}=3.50)$ and river water $(\mathrm{pH}=4.30)$, there is a tendency towards increasing acidity. This is not surprising because sulphate $\left(\mathrm{S}_{4}{ }^{2-}\right)$ anions exceed the acceptable limit of $100 \mathrm{mg} / \mathrm{l}$, which is an indication of probable acid deposition. 
Table 3: Mean value of water Quality of River, Harvested Rainwater and Borehole water in

\begin{tabular}{|c|c|c|c|c|}
\hline Parameters & Harvested Rainwater & Borehole water & River water & NDWQS (2007) \\
\hline & HR & $\mathrm{BH}$ & RW & \\
\hline Colour & 11.00 & 6.40 & 27.00 & $15 \mathrm{TCU}$ \\
\hline Odour & $\mathrm{U}$ & 0 & 0 & Uobjectionable \\
\hline Taste & U & 0 & 0 & Unobjectionable \\
\hline Temperature & 20 & 24 & 28 & Ambient \\
\hline Turbidity & 24 & 10 & 36 & $5 \mathrm{NTU}$ \\
\hline Conductivity & 1150.4 & $1,388.0$ & 1401.5 & $1000 \mu 5 / 1$ \\
\hline TDS & $717 . .30$ & 957.0 & 311.16 & $500 \mathrm{mg} / 1$ \\
\hline TSS & 126.65 & 56.1 & 326.04 & $500 \mathrm{mg} / 1$ \\
\hline TS & $843 . .95$ & 1013.1 & 637.20 & $500 \mathrm{mg} / 1$ \\
\hline $\mathrm{pH}$ & 3.50 & 8.65 & 4.30 & $6.5-8.5$ \\
\hline Barium & 0.1 & 0.00 & 0.14 & $0.7 \mathrm{mg} / 1$ \\
\hline Cadmium & 0.00 & 0.00 & 0.00 & $0.003 \mathrm{mg} / 1$ \\
\hline Chloride & 18.00 & 0.3 & 0.00 & $250 \mathrm{mg} / \mathrm{l}$ \\
\hline Copper & 0.09 & 0.21 & 0.07 & $1 \mathrm{mg} / 1$ \\
\hline Fluoride & 0.3 & 0.00 & 0.00 & $1.5 \mathrm{mg} / 1$ \\
\hline \multicolumn{5}{|l|}{ Total organic } \\
\hline Carbon content & 20.00 & 10.00 & 16.01 & $5 \mathrm{mg} / 1$ \\
\hline Total hardness & 615.6 & 714.32 & 1122.70 & $500 \mathrm{mg} / 1$ \\
\hline Iron & 0.00 & 0.35 & 1.58 & $0.03 \mathrm{mg} / 1$ \\
\hline Lead & 0.06 & 0.60 & 0.80 & $0.01 \mathrm{mg} / 1$ \\
\hline Magnesium & 1.02 & 0.63 & 0.83 & $0.2 \mathrm{mg} / \mathrm{l}$ \\
\hline Manganese & 0.03 & 0.62 & 0.80 & $0.2 \mathrm{mg} / 1$ \\
\hline Arsenic & 0.00 & 0.40 & 0.26 & $0.01 \mathrm{mg} / 1$ \\
\hline Mercury & 0.00 & 0.00 & 0.00 & $0.001 \mathrm{mg} / 1$ \\
\hline Ammonia & 0.00 & 0.02 & 0.71 & $0.5 \mathrm{mh} / 1$ \\
\hline Nitrate & $103 . .30$ & 141.14 & 97.11 & $50 \mathrm{mg} / 1$ \\
\hline Nitrite & 10.60 & 48.04 & 21.00 & $0.2 \mathrm{mg} / 1$ \\
\hline Sulphate & 215.00 & 159.06 & 346.71 & $100 \mathrm{mg} / 1$ \\
\hline Zinc & 0.03 & 0.00 & 0.00 & $3 \mathrm{mg} / \mathrm{l}$ \\
\hline Free chlorine & 0.01 & 0.03 & 0.11 & $0.2-0.25 \mathrm{mg} / 1$ \\
\hline TCC & 0 & 0 & $70 \mathrm{cf} / 100 \mathrm{ML}$ & $0 \mathrm{cf} / 100 \mathrm{ml}$ \\
\hline FCC & 0 & 0 & $21 \mathrm{cf} / 100 \mathrm{ML}$ & $0 \mathrm{cf} / 100 \mathrm{ml}$ \\
\hline
\end{tabular}

Legend: U - Unobjectionable; O - Objectionable; TSD - total dissolved solid, TSS - total suspended solid, TS - Total solid; TCC - total coliform count; FCC - faecal coliform count.

From table 3, the results of the chemical analysis show that cadmium and mercury are absent in the water samples. The barium content in water samples analyzed range from $0.00 \mathrm{mg} / \mathrm{l}$ in borehole water to $0.14 \mathrm{mg} / \mathrm{l}$ in river water. Harvested rainwater showed values of $0 / \mathrm{mg} / \mathrm{l}$. These values are all below the acceptable limit, which is $0.7 \mathrm{mg} / \mathrm{l}$. similarly, chloride, copper and fluoride indicate negligible presence in all three samples of drinking water sources.

The mean values of total hardness ranges from $615.6 \mathrm{mg} / 1$ to 1122.70 $\mathrm{mg} / \mathrm{l}$. These values are high and they all exceed the NDWQS (2007) acceptable limit. Total hardness for river water is $1122.70 \mathrm{mg} / \mathrm{l}$, for borehole water it is $714.32 \mathrm{mg} / \mathrm{l}$, and for harvested rainwater it is $615.6 \mathrm{mg} / \mathrm{l}$. These values exceed the acceptable limit of $500 \mathrm{mg} / \mathrm{l}$. The total carbon content exceeds the maximum acceptable limit of $5 \mathrm{mg} / \mathrm{l}$. The values are $10.00 \mathrm{mh} / 1$ for borehole water, $16.0 \mathrm{mg} / 1$ for river water and $20.00 \mathrm{mg} / 1$ for harvested rainwater. The mean values for conductivity, total hardness, TDS and TS 
indicate that the rainwater samples, borehole water and river water were generally high in electrolytes, highly buffered and relatively hard.

Other anions and cations analyzed are manganese $\left(\mathrm{Mn}^{+}\right)$magnesium $(\mathrm{Mg}$ $\left.{ }^{2+}\right)$, ammonia $\left(\mathrm{NH}_{4}^{+}\right)$; zinc $\left(\mathrm{Zn}^{+}\right)$, nitrate $\left(\mathrm{NO}_{4}^{-}\right)$, nitrate $\left(\mathrm{NO}_{3}^{-}\right)$and sulphate $\left(\mathrm{SO}_{4}{ }^{2-}\right)$. The ionic orders of dominance of the milliequivalent values of the major cations were magnesium (range X $0.63 \mathrm{mg} / \mathrm{l}-1.02 \mathrm{mg} / \mathrm{l}$ ), manganese (range $=0.03 \mathrm{mg} / 1-0.80 \mathrm{mg} / 1)$, ammonia (range $=0.00 \mathrm{mg} / 1-0.71 \mathrm{mg} / \mathrm{l})$ and zinc (ranges $=0.00 \mathrm{mg} / 1-0.03 \mathrm{mg} / \mathrm{l}$ ). For the anions, the ionic orders of dominance of the milliequivalent values are sulphate (range $=346.71 \mathrm{mg} / 1-159.06 \mathrm{mg} / \mathrm{l}$ ), nitrate $($ range $=141.14 \mathrm{mg} / \mathrm{l}-97.11 \mathrm{mg} / \mathrm{l})$, nitrite $($ range $=10.60 \mathrm{mg} / \mathrm{l}-48.04 \mathrm{mg} / \mathrm{l})$. These values confirm that for borehole water and river water samples the ionic contents exceed the maximum acceptable limit. However, for harvested rain water except for $\mathrm{Mn}^{+}$ions that is below the acceptable limit, all others exceed the maximum acceptable limit. The ionic value for iron is observed to be $0.35 \mathrm{mg} / 1$ for borehole water. For river water samples it is observed to be $1.58 \mathrm{mg} / 1$, however no traces are observed in harvested rainwater. Iron content is $0.00 \mathrm{mg} / \mathrm{l}$. Based on the foregoing findings, the potability of the drinking water with regards to the physical and chemical content reveal that it is not suitable for drinking. All water sources require adequate treatment before consumption.

From the microbiological analysis, table 3 reveals that total coliform and faecal coliform are zero for harvested rainwater and borehole water. This value is in agreement with the maximum acceptable value of $0 \mathrm{cf} / 100 \mathrm{ml}$ in accordance with NDWQS (2007). On the contrary the river water reveals values of $70 \mathrm{cf} / 100 \mathrm{ml}$ and $21 \mathrm{cf} / 100 \mathrm{ml}$ for total coliform count and faecal coliform count respectively. Based on the findings from microbiological analysis, the potability of river water is inadequate and therefore should not be used for drinking purposes. Thus, the implications for rural water development and management are that harvesting of rain water and borehole water should be given top priority by the arm of government responsible for provision of this facility in Akinima community. Appropriate technology for harnessing drinking water from these sources in view of the identified problems is important to reduce drastically the incidences of water-borne diseases.

\section{Hypotheses tested for the study:}

Two hypotheses were tested. These hypotheses were formulated to address the objectives of the study.

\section{Hypothesis I}

The Chi-square test was applied to test this hypothesis. The hypothesis sought to investigate whether there is any significant difference between the physical, chemical and microbiological parameters for the three major water 
sources, namely harvested rainwater, borehole water and river water, and the standardized values of the National Drinking water Quality Standard (2007). The chi-square computed is 32.68. The critical values at 0.01 and 0.05 are 15.086 and 11.070 respectively. Since the computed Chi-Square is greater than the critical values at 0.01 and 0.05 , the null hypothesis $\left(\mathrm{H}_{0}\right)$ is rejected and the alternative hypothesis $\left(\mathrm{H}_{1}\right)$ is accepted. Hence, it is concluded that there is a significant difference between the water quality from three major sources and the hypothesized NDWQS (2007).

\section{Hypothesis II}

One-way Analysis of variance (ANOVA) technique was applied to test the second hypothesis. This hypothesis sought to compare the physical, chemical and microbiological parameters for the three major sources of water supply to Akinima community. The Fcal (F-ratio) is 8.70. The critical value at 0.05 level of significance is 3.49 , and at 0.01 level of significance is 5.85 , at 2 degrees of freedom for the numerator and 20 degrees of freedom for the denominator. Since the Fcal (8.70) is greater than the F-critical values (3.49 and 5.85). $\mathrm{H}_{0}$ is rejected and $\mathrm{H}_{1}$ is accepted. Thus a significant variation exists between the mean values of the physical, chemical and microbiological parameters for the three major water sources. The acceptance of the alternative hypothesis does not, however allow us to specify which of the specific water sources is the best. In order to determine specifically which one of the various sources differ significantly the scheffe's test is applied. Since three sources were represented in the ANOVA technique performed, to get the scheffe's test three pairwise groups are compared. The sources are $\mathrm{X}_{1}$ - harvested rainwater, $\mathrm{X}_{2}$ - borehole water, $\mathrm{X}_{3}$ - river water. The scheffe's test $\left(\mathrm{F}_{\mathrm{s}}\right)$ is therefore computed to show the following three pairwise contrasts as $\mathrm{X}_{1}<\mathrm{X}_{2}, \mathrm{X}_{1}<\mathrm{X}_{3}, \mathrm{X}_{2}<\mathrm{X}_{3}$. The computed values are shown in table 5 .

Table 5: Scheffe's Test $\left(\mathrm{F}_{\mathrm{s}}\right)$ Showing Three Pairwise Test of Means.

\begin{tabular}{llll}
\hline Combinations & $\mathbf{X}_{\mathbf{1}} / \mathbf{X}_{\mathbf{2}}$ & $\mathbf{X}_{\mathbf{1}} / \mathbf{X}_{\mathbf{3}}$ & $\mathbf{X}_{\mathbf{2}} / \mathbf{X}_{\mathbf{3}}$ \\
\hline $\mathrm{Fs}$ & 30.43 & 36.82 & 3.41 \\
$\mathrm{~F}^{\prime}$ (that is F-Prime $=\mathrm{F}$ critical $\mathrm{X} \mathrm{df}$ & & & \\
In this case $\mathrm{F}^{\prime}=3.49 \mathrm{x} 2=6.98$ & & & \\
\hline Source: Author's Fieldwork. & &
\end{tabular}

From table 5, it is observed that the pairwise combination of $\mathrm{F}_{\mathrm{s}}$ (that is, Scheffe's test) for harvested rainwater $\left(X_{1}\right)$ and borehole water $\left(X_{2}\right)$ is 30.43 , for $X_{1}$ and $X_{3}$ it is 36.82 and for $X_{2}$ and $X_{3}$ it is 3.41. In comparing the $F^{\prime}$ (6.98) with the $F_{s}$ computed it shows that $X_{1}$ and $X_{2}$ are significantly different, also $X_{1}$ and $X_{3}$ are significantly different but $X_{2}$ and $X_{3}$ are not significantly different. Since $X_{1}$ differ significantly from $X_{2}$ and $X_{3}$, while $X_{2}$ and $\mathrm{X}_{3}$ do not differ significantly, it gives us the impetus to conclude that $\mathrm{X}_{1}$ which is harvested rainwater is the best source in Akinima Community. 
Management implication is that the technologies for harnessing rainwater should be developed, moreso as rainfall in this area is in abundant supply.

\section{CONCLUSION AND RECOMMENDATION}

This study investigated the problems associated with drinking water sources in Akinima community. Three major sources are identified. They are harvested rain water, borehole water and river water. Piped borne water supply is lacking. This situation is characteristic of many rural areas in Nigeria.

According to the data collated from laboratory analysis of water samples, the level of potability shows a significant difference from the NDWQS (2007). Also there exist significant variations in water quality between the three major sources. Scheffe's test gives the impetus to identify harvested rainwater as the most potable. Base on the findings the following management imperative are necessary:

- To properly harness the technologies to develop rainwater harvesting in the area.

- $\quad$ To build appropriate treatment plant for constant water quality assessment and monitoring.

- $\quad$ To build the capacity of manpower to manage and sustain the new technologies for harvesting rainwater.

The introduction of active Civil Society Organization (CSOs) intervention/participation in rural water supply.

\section{REFERENCES}

Bhatia, S. C. 2002. Environmental Chemistry, New Delhi, India, CBS Publishers and Distributors.

Cairncross; S. 1992, Sanitation and Water Supply: Practical lessons from the Decade New York, USA, Washington Inc.

Cunningham, W. P. and M. A. Cunningham. 2002. Principles of Environmental Sciences: Inquiry and Application, New York, USA; Mc Graw - Hill Company.

Ekop, O.B.1994. "Spatial Variation in Quality and Quantity of Public Water Supply in Calabar Municipality". Nigerian Journal of Technology and Environment (NNJE); Vol 11, Nos. 1 and 2 pp107-125.

Millennium Development Goals (MDG) 2000. Millennium Development Goals, www.un.org/documents/ga/res/55/a.55r002.pdf-A/RE/55/2

Millennium Development Goals (MDG). 2004. Millennium Development Goals Report 2004 Nigeria. Federal Republic of Nigeria.

National Population Commission (NPC). 2006 "National Population Commission Census 2006: National Summary". Federal Republic of Nigeria Official Gazette. Lagos. 
Nijavallirlt, N. H. and J. A., Sathaya. 2002. Climate Change and Developing Countries, New Delhi, India, Springer.

Poppe, W. and H. Rence 1997. Water Pollution. Water QUAL INT, pp 39-43.

Rosegrant, M. W.; X. Cai; and S. A. Cline. 2002. "World Water and Food 2025: Dealing with Scarcity.” International Food Policy Research Institute Washington DC, pp 1-15.

Tebutt, T. H. Y. 1990. Environmental Science: A study of Interrelationship. New York; McGraw Hill Company.

Thompson, G. R. and J. Turk, 2005. Earth Science and the Environment, Belmont, USA: Thomson Learning.

World Health Organization (WHO). 1996. "Guidelines for Drinking Water Quality: Health Criteria and Supporting Information Second Edition, Geneva, pp 37-38

World Health Organization (WHO)/United Nations Children's Fund (UNICEF). 2000. "Global Water Supply and Sanitation Assessment 2000 Report" The WHO and UNICEF Joint Monitoring Programme for Water Supply and Sanitation (JMP). Geneva, Switzerland.

World Health Organization (WHO): 1997. The International Standard for Dinking Water Qaulity. WHO Geneva, pp24-47.

WHO/UNICEF. 2004. "Meeting the MDG Drinking Water and Sanitation Target: A Mid - Term Assessment of Progress. The WHO and UNICEF Joint Monitoring Programme for Water Supply and Sanitation (JMP). Geneva, Switzerland. 